\title{
Chronic Pseudomonas aeruginosa Infection and Respiratory Muscle Impairment in Cystic Fibrosis
}

\author{
Theodore G Dassios MD, Anna Katelari MD, Stavros Doudounakis MD, \\ and Gabriel Dimitriou MD PhD
}

\begin{abstract}
BACKGROUND: Chronic infection with Pseudomonas aeruginosa in patients with cystic fibrosis (CF) is associated with increased morbidity. Chronic infection can cause limb and respiratory muscle compromise. Respiratory muscle function can be assessed via maximal inspiratory pressure $\left(\mathbf{P}_{\text {Imax }}\right)$, maximal expiratory pressure $\left(\mathbf{P}_{\text {Emax }}\right)$, and the pressure-time index of the respiratory muscles $\left(\mathbf{P T I}_{\text {mus }}\right)$. We studied the effect of chronic $P$. aeruginosa infection on respiratory muscle function in patients with CF. METHODS: This cross-sectional study assessed $\mathbf{P}_{\text {Imax }}, \mathbf{P}_{\text {Emax }}, \mathbf{P T I}_{\text {mus }}$, $\mathrm{FEV}_{1}$, FVC, maximum expiratory flow during the middle half of the FVC maneuver, body mass index, and upper arm muscle area in 122 subjects with $\mathrm{CF}$, in $\mathbf{4}$ subgroups matched for age and sex at different stages of $\boldsymbol{P}$. aeruginosa infection, according to the Leeds criteria. We compared respiratory muscle function in the subgroups according to $P$. aeruginosa infection state. RESULTS: Median $P_{I m a x}$ was significantly lower in CF subjects with chronic $P$. aeruginosa infection $\left(P_{\text {Imax }}=62 \mathrm{~cm} \mathrm{H} \mathrm{H}_{2} \mathrm{O}\right)$, compared to subjects who were never infected $\left(\mathrm{P}_{\text {Imax }}=86 \mathrm{~cm} \mathrm{H} \mathrm{H}_{2} \mathrm{O}, P=.02\right)$, free of infection $\left(P_{\text {Imax }}=74 \mathrm{~cm} \mathrm{H} \mathrm{H}_{2} \mathrm{O}, P=.01\right)$, or intermittently infected $\left(\mathrm{P}_{\text {Imax }}=72 \mathrm{~cm} \mathrm{H}_{2} \mathrm{O}\right.$, $P=.02)$. Median $P T I_{\text {mus }}$ was significantly increased in CF subjects with chronic $P$. aeruginosa infection $\left(\mathrm{PTI}_{\text {mus }}=.142\right)$, compared to subjects who were free of infection $\left(\mathrm{PTI}_{\text {mus }}=. \mathbf{1 0 2}, P=.006\right)$. Median upper-arm muscle area was significantly lower in CF subjects with chronic $P$. aeruginosa infection (upper-arm muscle area $=2,219 \mathrm{~mm}^{2}$ ), compared to subjects who were never infected $\left(2,754 \mathrm{~mm}^{2}, P=.03\right)$, free of infection $\left(2,678 \mathrm{~mm}^{2}, P=.01\right)$, or intermittently infected $\left(2,603 \mathrm{~mm}^{2}\right.$, $P=.04)$. Multivariate logistic regression revealed $P$. aeruginosa state of infection as a significant determinant of $\mathrm{PTI}_{\text {mus }}(P=.03)$ independently of sex, upper-arm muscle area, and $\mathrm{FEV}_{1}$. CONCLUSIONS: CF subjects with chronic $P$. aeruginosa infection exhibited impaired respiratory muscle function and decreased inspiratory muscle strength, and chronic $P$. aeruginosa infection independently impacts respiratory muscle function in subjects with CF. Key words: cystic fibrosis; respiratory muscles; Pseudomonas aeruginosa. [Respir Care 2014;59(3):363-370. (c) 2014 Daedalus Enterprises]
\end{abstract}

\section{Introduction}

Pseudomonas aeruginosa infection in patients with cystic fibrosis (CF) is a major determinant of lung disease, and is associated with severe pulmonary disease ${ }^{1}$ and increased morbidity and mortality. ${ }^{2} P$. aeruginosa infection is associated with gradually declining pulmonary status in children and young adults with $\mathrm{CF}$, as assessed by lung function studies. ${ }^{3,4}$ Furthermore, chronic pulmonary infec-

\footnotetext{
Correspondence: Theodore G Dassios MD, Addenbrooke's Hospital, Cambridge University Hospitals National Health Service Trust, Hills Road, Cambridge, CB2 0SW, United Kingdom. E-mail: tdassios@ upatras.gr.
}

DOI: $10.4187 /$ respcare.02549 
tion with $P$. aeruginosa is associated with deteriorating nutrition state, to the point of malnourishment. ${ }^{5}$ Sex differences relating to the natural history of $P$. aeruginosa infection have been described in the literature: women suffer higher rates of colonization and younger age of conversion to the more aggressive mucoid phenotype, compared to men. ${ }^{6,7}$ Chronic infection has been linked to compromised diaphragm function in animal models ${ }^{8}$ and human patients. ${ }^{9}$

Respiratory failure in CF is caused by parenchyma destruction, recurrent infection, and bronchiectasis, and respiratory muscle dysfunction might also play a critical role. Respiratory muscle compromise in CF can lead to respiratory muscle fatigue and thus contribute to respiratory failure. Respiratory muscle strength can be assessed by measurement of maximal inspiratory pressure $\left(\mathrm{P}_{\text {Imax }}\right)$ and maximal expiratory pressure $\left(\mathrm{P}_{\text {Emax }}\right) .{ }^{10}$ Respiratory muscle strength has been assessed in numerous studies, and conflicting evidence has been presented on whether it is decreased, maintained, or decreased in patients with $\mathrm{CF}$, as was recently highlighted. ${ }^{11}$ While some studies advocate that the chronically increased work load against which the respiratory muscles are forced to operate in CF exerts a conditioning effect, ${ }^{12}$ other studies support that chronic malnutrition and hyperinflation impact on respiratory muscle strength. ${ }^{13,14}$ Hyperinflation, airway obstruction, and malnutrition have been recognized as the major determinants of respiratory muscle compromise in CF patients. ${ }^{13-15}$

To our knowledge, the effect of chronic $P$. aeruginosa infection on respiratory muscle function has not been previously studied in $\mathrm{CF}$ patients. We hypothesized that $\mathrm{CF}$ patients chronically infected with $P$. aeruginosa would have impaired respiratory muscle function, compared to CF patients who are not chronically infected. Our aim was to compare respiratory muscle function by measurement of $\mathrm{P}_{\text {Imax }}, \mathrm{P}_{\text {Emax }}$, and the pressure-time index of the respiratory muscles $\left(\mathrm{PTI}_{\text {mus }}\right)$ between $\mathrm{CF}$ patients at different stages of $P$. aeruginosa infection in a large cohort of children and young adults.

\section{Methods}

This study was approved by the ethics committee of, and performed at, Aghia Sophia Children's Hospital, Athens, Greece. All subjects, or their parents or legal guardians, gave informed written consent prior to the study.

\section{Subjects}

We recruited subjects from patients attending their follow-up appointments in our CF department. CF diagnosis was confirmed by sweat-test and expanded mutation analysis. All the subjects received standard daily chest physical therapy. We excluded patients who were unable to

\section{QUICK LOOK}

\section{Current knowledge}

Chronic infection with Pseudomonas aeruginosa in patients with cystic fibrosis is associated with increased morbidity, including limb and respiratory muscle dysfunction.

\section{What this paper contributes to our knowledge}

Cystic fibrosis patients with chronic $P$. aeruginosa infection had impaired respiratory muscle function and decreased inspiratory muscle strength. Chronic $P$. aeruginosa infection independently impacted respiratory muscle function in patients with cystic fibrosis.

perform reproducible lung function tests; patients who had an exacerbation during the month prior to assessment; ${ }^{16}$ patients on steroids, anti-inflammatories, or azithromycin; and patients who had positive respiratory cultures for Aspergillus species, Stenotrophomonas species, Scedosporium species, Burkholderia species, methicillin-resistant Staphylococcus aureus, or any pathogen other than S. aureus and Haemophilus influenzae in the 5 years prior.

\section{Sample Size}

Power analysis was conducted to determine the sample size required to identify PTI $_{\text {mus }}$ differences between 4 subgroups: never had $P$. aeruginosa infection; no $P$. aeruginosa infection at assessment; intermittent $P$. aeruginosa infection; and chronic $P$. aeruginosa infection. The $\mathrm{PTI}_{\text {mus }}$ standard deviation was set at 0.03. ${ }^{15}$ The power analysis indicated that detecting a $\mathrm{PTI}_{\text {mus }}$ increase of 0.05 at a power of 0.9 and a statistical significance of $P<.05$ would require 8 subjects in each subgroup.

\section{Measurements}

Flow was recorded with a pneumotachograph (Mercury F100L, GM Instruments, Kilwinning, Scotland) connected to a differential pressure transducer (DP45, Validyne Engineering, Northridge, California, range $\pm 3.5 \mathrm{~cm} \mathrm{H}_{2} \mathrm{O}$ ). Airway pressure was measured from a side port on the pneumotachograph, with a differential pressure transducer (DP45, Validyne Engineering, Northridge, California, range $\pm 225 \mathrm{~cm} \mathrm{H} \mathrm{H}_{2} \mathrm{O}$ ). A carrier amplifier (CD280, Validyne Engineering, Northridge, California) was used to amplify the signals from the differential pressure transducers. The amplified signals were recorded with analog-to-digital sampling at $100 \mathrm{~Hz}$ (NI PCI-6036E, National Instruments, 
Austin, Texas) and analyzed with data analysis software (Labview, National Instruments, Austin, Texas).

\section{Respiratory Pressures}

We measured $\mathrm{P}_{\text {Imax }}, \mathrm{P}_{\text {Emax }}$, airway-occlusion pressure at $0.1 \mathrm{~s}$ after the start of inspiration $\left(\mathrm{P}_{0.1}\right)$, breathing frequency, tidal volume, minute ventilation, inspiratory time $\left(\mathrm{T}_{\mathrm{I}}\right)$, and total breathing cycle time $\left(\mathrm{T}_{\text {tot }}\right) . \mathrm{P}_{0.1}$ was measured during quiet breathing; at least 5 airway occlusions were performed, and the average $\mathrm{P}_{0.1}$ value was calculated. $\mathrm{P}_{\text {Imax }}$ was measured starting at residual volume, with a maximal inspiratory effort against an occluded airway. ${ }^{17}$ $\mathrm{P}_{\text {Emax }}$ was measured starting at total lung capacity, with a maximal expiratory effort against an occluded airway. ${ }^{17}$ Five maximal reproducible respiratory efforts were performed, and the maximum value was recorded. ${ }^{10}$ The occlusions were performed with a unidirectional valve connected to the mouthpiece (total dead space $8 \mathrm{~mL}$ ). Care was taken to eliminate any leak around the mouthpiece; a small leak prevented artificial glottic closure. ${ }^{10}$ Only $\mathrm{P}_{\text {Imax }}$ and $\mathrm{P}_{\text {Emax }}$ maneuvers with plateau pressure for at least $1 \mathrm{~s}$ were accepted for analysis. ${ }^{10} \mathrm{We}$ also calculated the percent-of-predicted $\mathrm{P}_{\mathrm{Imax}}$ and $\mathrm{P}_{\mathrm{Emax}}$ values. ${ }^{18}$

\section{Pressure-Time Index of the Respiratory Muscles}

Respiratory muscle function was evaluated as $\mathrm{PTI}_{\text {mus }}$, calculated as:

$$
\mathrm{PTI}_{\text {mus }}=\left(\text { mean } \mathrm{P}_{\mathrm{I}} / \mathrm{P}_{\text {Imax }}\right) \times\left(\mathrm{T}_{\mathrm{I}} / \mathrm{T}_{\text {tot }}\right)
$$

where $\mathrm{P}_{\mathrm{I}}$ is airway pressure during inspiration, calculated as

$$
\mathrm{P}_{\mathrm{I}}=5 \times \mathrm{P}_{0.1} \times \mathrm{T}_{\mathrm{I}}
$$

$\mathrm{PTI}_{\text {mus }}$ is a composite index of respiratory muscle function ${ }^{15,19}$ that describes the efficiency of the respiratory muscles and the balance between neuromuscular competence and respiratory load. A higher PTI mus indicates inefficient respiratory muscle function and is related to increased risk of respiratory muscle fatigue. ${ }^{20}$

\section{Lung Function Tests}

$\mathrm{FEV}_{1}$, maximal expiratory flow during the middle half of the FVC maneuver, and FVC were measured (MasterScreen, Erich Jaeger/CareFusion, San Diego, California) per the European Respiratory Society guidelines, and are expressed as percent-of-predicted values. ${ }^{21,22}$ The values recorded were those achieved before the use of bronchodilator drugs.

\section{Nutrition Assessment}

Height and weight were measured, and the corresponding body mass index (BMI) and BMI Z score were calculated. ${ }^{23}$ Midarm muscle circumference was measured halfway between the acromion and the olecranon to the nearest centimeter, right hand hanging relaxed. ${ }^{24}$ Triceps skinfold thickness was measured (Harpenden Skinfold Caliper, Baty International, West Sussex, United Kingdom) to the nearest millimeter, halfway over the triceps muscle, skinfold parallel to the upper arm longitudinal axis. ${ }^{24}$ Upper-arm muscle area was calculated from the midarm muscle circumference and triceps skinfold thickness. ${ }^{25}$

\section{Classification of $P$. aeruginosa Infection State}

The Leeds criteria were used to classify $P$. aeruginosa infection state. ${ }^{26}$ The infection was classified as chronic when $>50 \%$ of the months sampled had $P$. aeruginosa positive culture; intermittent when $\leq 50 \%$ of the months sampled had $P$. aeruginosa positive culture; free of infection when $P$. aeruginosa culture had been negative over the previous 12 months, after having previously been $P$. aeruginosa culture positive; and never infected when $P$. aeruginosa had never been cultured from sputum or cough swab. At least 6 airway cultures were acquired in separate months over the year before the assessment. ${ }^{26}$ Sputum was collected in sterile disposable containers, stored at ambient temperature, and processed within $4 \mathrm{~h}$ from collection. Sputum samples were inoculated and incubated aerobically at $37^{\circ} \mathrm{C}$ for 48 hours, then analyzed for $P$. aeruginosa and other pathogens. $P$. aeruginosa positive cultures were identified as either mucoid or non-mucoid phenotype.

All the subjects who were chronically infected with $P$. aeruginosa were regularly treated with inhaled antibiotics.

\section{Protocol}

All the subjects were assessed in the same setting, with the same medical instruments. All the subjects were in stable clinical condition and had received their medications as usual. They were evaluated in the morning hours, and the assessments were in the following order: nutrition assessment, pulmonary function testing, respiratory muscle assessment. All the subjects were evaluated in a sitting position, and a nose clip was used in the pulmonary function and respiratory muscle studies.

\section{Statistical Analysis}

Data were checked for normality with the KolmogorovSmirnoff and Shapiro-Wilk tests. Differences between 
groups were assessed for significance with the KruskalWallis rank-sum test and the Pearson chi-square test, as appropriate. If a significant difference was detected, the Mann-Whitney rank-sum test was used for subsequent pairwise comparisons between the subgroups. Multivariate logistic regression was performed to determine which variables contribute to alterations of PTI mus. $P<.05$ was considered a significant difference. Statistical analysis was performed with statistics software (SPSS 17.0, SPSS, Chicago, Illinois).

\section{Results}

\section{Subjects}

Between October 2009 and June 2010, 122 subjects (68 male) were included in the study. The median age was 13 y (IQR $10-17 \mathrm{y}$ ), and 13 subjects were $>19$ years old. The median BMI Z score was 0.22 (IQR -0.49 to 0.84 ). The median percent-of-predicted $\mathrm{FEV}_{1}$ was $99 \%$ (IQR 75$119 \%)$.

The 4 subgroups were matched for age and sex: group 1 consisted of 11 subjects that had never been infected by $P$. aeruginosa, group 2 consisted of 33 subjects who were free of $P$. aeruginosa infection at the time of assessment, group 3 consisted of 39 subjects with intermittent $P$. aeruginosa infection, and group 4 consisted of 39 subjects with chronic $P$. aeruginosa infection. As the power analysis showed that 8 subjects in each group were required, the sample size per group was deemed appropriate. In group 4, 17 of 39 subjects (43.6\%) were chronically infected with the mucoid $P$. aeruginosa phenotype. Since the data were not normally distributed, non-parametric tests were applied to compare the subgroups.

\section{Anthropometry and Nutrition}

There were no significant differences in height or weight between the 4 subgroups (Table 1). There were significant differences in BMI $\mathrm{Z}$ score between the 4 subgroups $(P=.02)$. Post hoc analysis revealed that the median BMI $\mathrm{Z}$ score was significantly lower in group 4 than in group 1 $(P=.009)$ or group $3(P=.02)$. There were significant differences between the 4 groups in midarm muscle circumference $(P=.001)$, triceps skinfold thickness $(P=.02)$, and upper-arm muscle area $(P=.03)$. Post hoc analysis revealed significantly lower midarm muscle circumference in group 4 than in group $1(P=.003)$, group $2(P=.003)$, or group $3(P=.002)$, and significantly lower triceps skinfold thickness in group 4 than in group $2(P=.05)$ or group $3(P=.006)$.

\section{Lung Function, Respiratory Muscle Function, and Breathing Cycle Components}

There were no significant differences between the 4 subgroups in breathing frequency, tidal volume, tidal volume per kilogram, minute ventilation, inspiratory flow, $\mathrm{T}_{\mathrm{I}}$, $\mathrm{T}_{\text {tot }}, \mathrm{T}_{\mathrm{I}} / \mathrm{T}_{\text {tot }}, \mathrm{P}_{0.1}$, mean $\mathrm{P}_{\mathrm{I}}$, or $\mathrm{P}_{\text {Emax }}$. There were significant differences in $\mathrm{P}_{\operatorname{Imax}}$ (Fig. 1) and percent-of-predicted $\mathrm{P}_{\text {Imax }}$ $(P=.043$ and .037 , respectively), and post hoc analysis revealed significantly lower $\mathrm{P}_{\text {Imax }}$ in group 4 than in group 1 $(P=.044)$, group $2(P=.01)$, or group $3(P=.046)$, and significantly lower percent-of-predicted $\mathrm{P}_{\text {Imax }}$ in group 4 than in group $2(P=.009)$ or group $3(P=.02)$. Nonparametric testing revealed significant differences in mean $\mathrm{P}_{\mathrm{I}} / \mathrm{P}_{\text {Imax }}$ and $\mathrm{PTI}_{\text {mus }}(P=.02$ and $P=.03$, respectively $)$. The mean $\mathrm{P}_{\mathrm{I}} / \mathrm{P}_{\mathrm{Imax}}$ was significantly lower in group 4 than in group $2(P=.005)$, and $\mathrm{PTI}_{\text {mus }}$ (Fig. 2) was significantly higher in group 4 than in group $2(P=.006)$. In group 4 the subjects who had mucoid $P$. aeruginosa had a median $\mathrm{P}_{\text {Imax }}$ of $59 \mathrm{~cm} \mathrm{H}_{2} \mathrm{O}$, whereas the group- 4 subjects who had non-mucoid $P$. aeruginosa had a median $\mathrm{P}_{\mathrm{Imax}}$ of $66 \mathrm{~cm} \mathrm{H}_{2} \mathrm{O}(P=.15)$.

Multivariate logistic regression analysis revealed that $P$. aeruginosa infection state was significantly related to $\mathrm{PTI}_{\text {mus }}$, independently of $\mathrm{FEV}_{1}$, upper-arm muscle area, and sex (Table 2).

\section{Discussion}

Our study found that $\mathrm{PTI}_{\text {mus }}$ was significantly increased and $\mathrm{P}_{\text {Imax }}$ was significantly decreased in $\mathrm{CF}$ subjects with chronic $P$. aeruginosa infection, compared to those who were free, never infected, or intermittently infected. The chronically infected patients also had compromised somatic muscular indices, such as midarm muscle circumference and upper-arm muscle area.

Our results suggest that chronic $P$. aeruginosa infection impacts respiratory muscle function in the context of normal lung-function parameters, probably identifying chronic $P$. aeruginosa infection as an independent determinant of respiratory muscle compromise in CF. Our findings emphasize the multifactorial origin of respiratory muscle impairment in the pathophysiology of respiratory failure in CF.

Chronic pulmonary infection with $P$. aeruginosa affects the majority of $\mathrm{CF}$ subjects by adulthood, ${ }^{27}$ and increases mortality and morbidity in $\mathrm{CF}$ patients, ${ }^{2}$ and harms pulmonary status in children with CF. ${ }^{3} P$. aeruginosa plays a central role in the vicious cycle of pulmonary infection, pulmonary inflammation, lung tissue damage, and consequent respiratory failure. 28

Although systemic inflammation is not a major component of CF disease, pulmonary inflammation has been suspected to cause limb and respiratory muscle wasting and 
Table 1. Anthropometric, Pulmonary, and Respiratory Muscle Function Data According to Different Stages of Pseudomonas aeruginosa Infection

\begin{tabular}{|c|c|c|c|c|}
\hline & Group $1(n=11)$ & Group $2(n=33)$ & Group $3(n=39)$ & Group $4(n=39)$ \\
\hline Male, no. (\%) & $6(54.5)$ & $19(57.6)$ & $23(58.9)$ & $20(51.3)$ \\
\hline Age, y & $15(8-26)$ & $13(11-17)$ & $13(10-15)$ & $14(11-17)$ \\
\hline Height, cm & $160(130-166)$ & $159(140-165)$ & $153(135-162)$ & $156(138-168)$ \\
\hline Weight, kg & $52(32-61)$ & $48(36-61)$ & $48(31-58)$ & $44(34-55)$ \\
\hline Body mass index $\mathrm{Z}$ score* & $0.81(0.10-1.22)$ & $0.04(-0.61-0.87)$ & $0.29(-0.15-1.07)$ & $-0.13(-0.88-0.15) \dagger$ \\
\hline Midarm muscle circumference, $\mathrm{cm}^{*}$ & $24(21-27)$ & $23(19-25)$ & $23(20-25)$ & $20(17-22) \ddagger$ \\
\hline Triceps skinfold thickness, mm* & $13(9-15)$ & $13(8-15)$ & $12(10-17)$ & $11(7-13) \S$ \\
\hline Upper-arm muscle area, $\mathrm{mm}^{2} *$ & $2754(2111-3359)$ & $2678(2063-3522)$ & $2603(1784-3257)$ & $2219(1578-2670) \ddagger$ \\
\hline FVC, $\%$ predicted & $112(81-125)$ & $105(96-115)$ & 109 (90-119) & $96(74-112)$ \\
\hline $\mathrm{FEV}_{1}, \%$ predicted & $107(88-125)$ & $99(80-118)$ & $99(72-124)$ & $95(63-116)$ \\
\hline $\mathrm{MEF}_{25-75}, \%$ predicted & $98(70-124)$ & $71(47-102)$ & $78(39-115)$ & $68(34-105)$ \\
\hline Breathing frequency, breaths/min & $18(16-19)$ & $17(15-22)$ & $16(15-21)$ & $19(16-23)$ \\
\hline Tidal volume, $\mathrm{L}$ & $0.72(0.37-0.82)$ & $0.52(0.41-0.62)$ & $0.48(0.37-0.70)$ & $0.48(0.36-0.69)$ \\
\hline Tidal volume, $\mathrm{mL} / \mathrm{kg}$ & $13.9(6.0-17.1)$ & $10.9(8.8-14.7)$ & $10.3(7.7-14.8)$ & $10.3(8.8-14.0)$ \\
\hline Minute ventilation, $\mathrm{L} / \mathrm{min}$ & $8.64(7.22-13.68)$ & $9.69(7.25-11.03)$ & $8.63(6.56-11.33)$ & $9.31(6.80-11.52)$ \\
\hline Inspiratory flow, L/s & $0.323(0.255-0.525)$ & $0.344(0.282-0.435)$ & $0.318(0.270-0.408)$ & $0.350(0.257-0.427)$ \\
\hline $\mathrm{T}_{\mathrm{I}}, \mathrm{s}$ & $1.49(1.22-1.52)$ & $1.50(1.20-1.84)$ & $1.53(1.31-1.84)$ & $1.39(1.10-1.56)$ \\
\hline $\mathrm{T}_{\text {tot }}, \mathrm{s}$ & $3.29(3.06-3.56)$ & $3.37(2.65-4.16)$ & $3.40(2.82-4.16)$ & $3.15(2.62-3.64)$ \\
\hline $\mathrm{T}_{\mathrm{I}} / \mathrm{T}_{\text {tot }}$ & $0.45(0.43-0.47)$ & $0.44(0.42-0.47)$ & $0.45(0.43-0.47)$ & $0.44(0.41-0.46)$ \\
\hline $\mathrm{P}_{0.1}, \mathrm{~cm} \mathrm{H}_{2} \mathrm{O}$ & $2.18(1.37-3.74)$ & $2.28(1.78-3.04)$ & $2.51(1.76-3.88)$ & $2.76(1.95-3.91)$ \\
\hline \multicolumn{5}{|l|}{ Inspiratory pressures } \\
\hline Mean, $\mathrm{cm} \mathrm{H}_{2} \mathrm{O}$ & $17.8(8.9-24.9)$ & $17.9(12.9-24.5)$ & $18.6(13.5-26.4)$ & $20.5(13.2-28.4)$ \\
\hline Maximum, cm $\mathrm{H}_{2} \mathrm{O}^{*}$ & $86(56-103)$ & $74(62-93)$ & $72(55-97)$ & $62(48-78) \ddagger$ \\
\hline Maximum, $\%$ predicted $*$ & $100(82-124)$ & $96(85-123)$ & $99(85-126)$ & $82(63-114) \S$ \\
\hline Mean/maximum* & $0.208(0.137-0.307)$ & $0.220(0.146-0.335)$ & $0.261(0.179-0.376)$ & $0.317(0.213-0.460) \|$ \\
\hline Pressure-time index of the respiratory muscles* & $0.097(0.067-0.131)$ & $0.102(0.063-0.149)$ & $0.116(0.080-0.175)$ & $0.142(0.097-0.190) \|$ \\
\hline \multicolumn{5}{|l|}{ Expiratory pressures } \\
\hline Maximum, $\mathrm{cm} \mathrm{H}_{2} \mathrm{O}$ & $71(50-108)$ & $75(50-95)$ & $66(49-96)$ & $62(46-84)$ \\
\hline Maximum, $\%$ predicted & $69(60-119)$ & $75(59-89)$ & $78(57-101)$ & $69(51-80)$ \\
\hline \multicolumn{5}{|c|}{$\begin{array}{l}\text { Values are median (IQR) unless otherwise indicated. } \\
* P<.05 \text { via Kruskal-Wallis test, for differences between the } P \text {. aeruginosa groups. } \\
\dagger P<.05 \text { via Mann-Whitney post hoc test for group } 4 \text { versus groups } 1 \text { and } 3 \text {. } \\
¥ P<.05 \text { via Mann-Whitney post hoc test for group } 4 \text { versus all other groups. } \\
\S P<.05 \text { via Mann-Whitney post hoc test for group } 4 \text { versus groups } 2 \text { and } 3 . \\
\| P=.01 \text { via Mann-Whitney post hoc test for group } 4 \text { versus group } 2 . \\
\mathrm{MEF}_{25-75} \text { = maximum expiratory flow during the middle half of the } \mathrm{FVC} \text { maneuver } \\
\mathrm{T}_{\mathrm{I}}=\text { inspiratory time } \\
\mathrm{T}_{\text {tot }}=\text { total breathing cycle time } \\
\mathrm{P}_{0.1}=\text { airway-occlusion pressure } 0.1 \mathrm{~s} \text { after the start of inspiratory flow }\end{array}$} \\
\hline
\end{tabular}

weakness via "spill-over" of inflammatory mediators. Pulmonary inflammation and consequent injury is linked to systemic inflammation in patients with COPD, ${ }^{29}$ and increased circulating inflammatory markers have been detected in $\mathrm{CF}$ subjects. ${ }^{30,31}$ Infection induces respiratory muscle weakness in animal models, ${ }^{32}$ and respiratory muscle weakness is associated with upper-respiratory-tract infections in humans. ${ }^{33}$ Induced chronic bronchopulmonary infection by $P$. aeruginosa significantly decreased diaphragm and limb strength in infected mice, ${ }^{28}$ and tumor necrosis factor alpha depressed the diaphragmatic tetanic force in murine diaphragm and limb muscle preparations. ${ }^{8}$ Furthermore, in mice, endotoxin caused diaphragm weakness and contractile dysfunction. ${ }^{34}$
Respiratory muscle function is compromised in $\mathrm{CF}$, according to some studies, which reported decreased maximal respiratory pressures in hyperinflated, malnourished CF patients with airway obstruction. ${ }^{13-15,35} \mathrm{PTI}_{\text {mus }}$ was abnormal in $\mathrm{CF}$ patients, indicating respiratory muscle impairment related to nutritional compromise, decreased somatic muscle mass, hyperinflation, and airway obstruction. ${ }^{13-15}$

In our study, $\mathrm{PTI}_{\text {mus }}$ was selected to describe respiratory muscle function because it is measured noninvasively and it is a global respiratory-muscles index that incorporates properties of time, respiratory load, and neuromuscular competence. ${ }^{20}$ As a limitation of $\mathrm{PTI}_{\text {mus }}$ in $\mathrm{CF}$ we should mention that measurement of $\mathrm{P}_{0.1}$ might be affected by the 


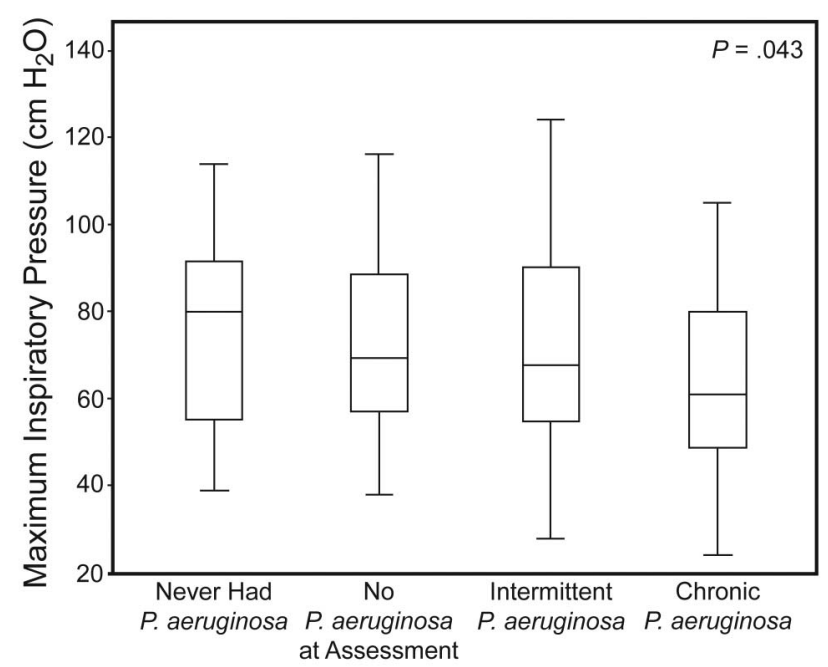

Fig. 1. Maximum inspiratory pressure in 4 subgroups of patients with cystic fibrosis. In each data bar the horizontal line represents the median, the bottoms and tops of the bars represent the 25th and 75th percentiles, and the whisker bars represent the 5th and 95th percentiles. $P=.043$ for the comparison of all the groups.

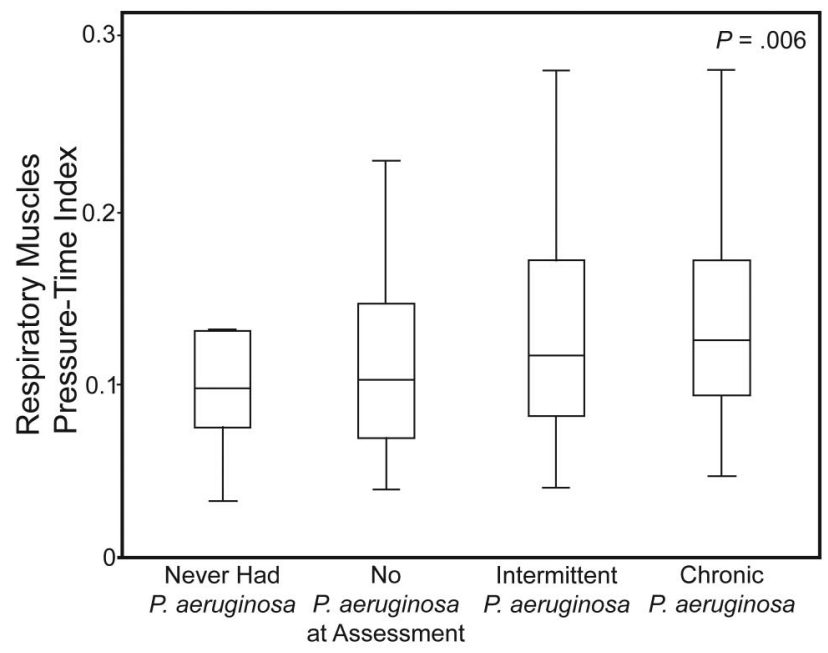

Fig. 2. Pressure-time index of the respiratory muscles in 4 subgroups of patients with cystic fibrosis. In each data bar the horizontal line represents the median, the bottoms and tops of the bars represent the 25th and 75 th percentiles, and the whisker bars represent the 5th and 95th percentiles. $P=.006$ for the comparison of all the groups.

increased time-constant of the CF lung and the ensuing delayed transmission of the pressure changes from the alveoli to the mouth, as exhibited in COPD subjects. ${ }^{36}$ Sniff nasal inspiratory pressure has been proposed as an alternative noninvasive test of respiratory muscle function in CF, but nasal inspiratory pressure underestimates esophageal pressure, probably because of nasal obstruction and dampening of the pressure changes secondary to the increased time-constant of the CF lung. ${ }^{37}$
Table 2. Multivariate Logistic Regression Analysis With PressureTime Index of the Respiratory Muscles as the Outcome Variable

\begin{tabular}{lrcc}
\hline \hline & $95 \% \mathrm{CI}$ & $\begin{array}{c}\text { Standardized } \\
\text { Coefficient }\end{array}$ & $P$ \\
\hline $\mathrm{FEV}_{1}, \%$ predicted & 0.000 to 0.000 & -0.128 & .17 \\
Upper-arm muscle area & 0.000 to 0.000 & -0.087 & .37 \\
Sex & -0.043 to 0.009 & -0.120 & .20 \\
$P$. aeruginosa infection state & 0.002 to 0.029 & 0.210 & .03 \\
\hline
\end{tabular}

BMI Z score, midarm muscle circumference, and upperarm muscle area were significantly decreased in our CF subjects with chronic $P$. aeruginosa infection. Muscular indices and lean body mass correlate well with respiratory muscle indices. ${ }^{15}$ It has been suggested that decreased muscular synthesis and impaired muscle regeneration occur in the presence of abundant pro-inflammatory cytokines in the chronically infected lung, which spill over and cause chronic systemic inflammation. ${ }^{38}$

Recent work addressed sex differences in the course of $P$. aeruginosa infection in patients with $\mathrm{CF}$, and highlighted that estrogen induces mucoid conversion of $P$. aeruginosa in women with $\mathrm{CF}$ and is associated with more frequent exacerbations. ${ }^{6}$ On the other hand, male $\mathrm{CF}$ patients with impaired skeletal muscle strength have normal testosterone levels. ${ }^{39}$ Mucoid conversion of $P$. aeruginosa in CF is associated with resistance to antibiotics and increased morbidity and mortality. ${ }^{40}$ In the present study, which was not designed to address those questions, sex and the mucoid state of $P$. aeruginosa were not significant determinants of respiratory muscle function in $\mathrm{CF}$ subjects. The lack of statistical difference in $\mathrm{P}_{\text {Imax }}$ between subjects infected with mucoid versus non-mucoid $P$. aeruginosa raises the question of whether muscle weakness is the result of the chronic disease itself rather than the $P$. aeruginosa infection state. Of note, $\mathrm{P}_{\text {Imax }}$ in CF subjects chronically infected with the non-mucoid strain was nonsignificantly higher than in CF subjects chronically infected with the mucoid strain. This might represent the course of disease progression in $\mathrm{CF}$, reflecting mucoid-strain conversion and increasing disease severity with age.

Compared to previous studies, our study reports similar maximal respiratory pressure and $\mathrm{PTI}_{\text {mus }}$ values. $\mathrm{P}_{\mathrm{Emax}}$ was not significantly different between the 4 subgroups, which might indicate a preferential action of chronic $P$. aeruginosa infection on the diaphragm rather than on the expiratory muscles, which might be explained by way of proximity. A preferential-to-the-diaphragm weakness was demonstrated in induced sustained $P$. aeruginosa infection in animal models. ${ }^{28}$

Our subjects had good lung function, probably due to idiosyncratic reasons. This was not deliberately done, although enrollment was limited to stable out-patients. Fur- 
thermore, our study included younger subjects than have previous studies, ${ }^{14,15,38}$ who probably (due to limited disease progression) had milder lung disease, implying that further investigation in older CF patients with lower baseline lung function may demonstrate an even more pronounced effect.

Adult CF patients with severe lung disease have increased diaphragm thickness and inspiratory strength, ${ }^{38}$ probably as a result of the training effect that the chronically increased respiratory load imposes on the respiratory muscles. In these patients inflammation was not identified as a predictor of respiratory muscle compromise, whereas fat-free mass and airway resistance were. ${ }^{38}$ In our cohort of CF subjects with mild lung disease, diaphragm thickening might have not yet occurred, and the respiratory muscles might have been exposed to the deleterious effects of chronic infection and malnutrition in the absence of a counterbalancing diaphragm thickening mechanism.

\section{Limitations}

At present, no definition of chronic $P$. aeruginosa infection has been universally accepted. In keeping with defining chronic infection as an infectious process that persists despite appropriate therapy, chronic infection could be more accurately described by persistent pathological and immune marker abnormalities. ${ }^{26}$ Due to technical limitations we were unable to collect data on functional residual capacity, precluding the possibility of incorporating hyperinflation as another factor that probably contributes to respiratory muscle impairment in $\mathrm{CF}$, as suggested in previous studies. ${ }^{14,15}$ Furthermore, it is possible that the lack of lung-function and breathing-cycle differences between the groups was largely because all our subjects were in good pulmonary condition, and if more debilitated subjects had been included more differences might have emerged. We acknowledge this as a probable bias, since CF subjects with more severe lung disease could have respiratory muscle impairment secondary to marked airway obstruction and hyperinflation, on top of the impairment caused by chronic $P$. aeruginosa infection. Thus, our selection of a mildly lung-function-impaired cohort might have affected the results and their applicability in the CF community. Finally, although subjects with various other pathogens were excluded, for logistical reasons we did not exclude subjects infected with $S$. aureus or $H$. influenzae, because such a cohort could not be empowered for statistical analysis, nor did we apply polymerase-chain-reaction testing in the assessment of sputum samples. Therefore the contribution of $S$. aureus and $H$. influenzae to our results cannot be safely refuted; however, in practical terms, obtaining enough patients for such a cohort would be very challenging for any $\mathrm{CF}$ center. Although it is possible that co-infected CF subjects have worse outcomes, both $S$. aureus and $H$. influenzae are frequently found early on in CF patients, and their contribution to CF lungdisease progression and respiratory muscle impairment has not been clearly delineated.

\section{Clinical Applicability}

Identifying chronic $P$. aeruginosa infection as an independent predictor of respiratory muscle compromise implies that aggressive eradication of $P$. aeruginosa might help delay respiratory muscle fatigue and respiratory failure in patients with CF. Patients chronically infected with $P$. aeruginosa could be targeted for respiratory muscle function testing, especially if they have other risk factors, such as malnutrition, hyperinflation, or airway obstruction. Treatments that alleviate respiratory load and decrease the work of breathing, such as noninvasive ventilation, ${ }^{41}$ inspiratory muscle training, and aerobic exercise, could then be initiated on the basis of the respiratory muscle function condition.

\section{Conclusions}

CF patients with chronic P. aeruginosa infection had impaired respiratory muscle function. Maximal inspiratory pressure was significantly lower and $\mathrm{PTI}_{\text {mus }}$ was significantly higher in CF subjects with chronic $P$. aeruginosa infection than in those without chronic $P$. aeruginosa infection. Midarm muscle circumference and upper-arm muscle area were significantly lower in subjects with chronic $P$. aeruginosa infection than in subjects who had never been infected, were currently free of infection, or had intermittent infection with $P$. aeruginosa. Chronic $P$. aeruginosa infection might be an independent determinant of respiratory muscle compromise in patients with $\mathrm{CF}$.

\section{ACKNOWLEDGMENTS}

We thank Richard Parker PhD, Centre for Applied Medical Statistics, University of Cambridge, United Kingdom, for assistance with the statistical analysis.

\section{REFERENCES}

1. Nixon GM, Armstrong DS, Carzino R, Carlin JB, Olinsky A, Robertson CF, et al. Clinical outcome after early Pseudomonas aeruginosa infection in cystic fibrosis. J Pediatr 2001;138(5):699-704.

2. Emerson J, Rosenfeld M, McNamara S, Ramsey B, Gibson RL. Pseudomonas aeruginosa and other predictors of mortality and morbidity in young children with cystic fibrosis. Pediatr Pulmonol 2002; 34(2):91-100.

3. Kosorok MR, Zeng L, West SE, Rock MJ, Splaingard ML, Laxova A, et al. Acceleration of lung disease in children with cystic fibrosis after Pseudomonas aeruginosa acquisition. Pediatr Pulmonol 2001; 32(4):277-287.

4. Vandenbranden SL, McMullen A, Schechter MS, Pasta DJ, Michaelis RL, Konstan MW, et al. Lung function decline from ad- 
olescence to young adulthood in cystic fibrosis. Pediatr Pulmonol 2012;47(2):135-143.

5. Al-Aloul M, Crawley J, Winstanley C, Hart CA, Ledson MJ, Walshaw MJ. Increased morbidity associated with chronic infection by an epidemic Pseudomonas aeruginosa strain in CF patients. Thorax 2004;59(4):334-336.

6. Chotirmall SH, Smith SG, Gunaratnam C, Cosgrove S, Dimitrov BD, O'Neill SJ, et al. Effect of estrogen on Pseudomonas mucoidy and exacerbations in cystic fibrosis. N Engl J Med 2012;366(21): 1978-1986.

7. Levy H, Kalish LA, Cannon CL, Garcia KC, Gerard C, Goldmann D, et al. Predictors of mucoid Pseudomonas colonization in cystic fibrosis patients. Pediatr Pulmonol 2008;43(5):463-471.

8. Reid MB, Lannergren J, Westerblad H. Respiratory and limb muscle weakness induced by tumor necrosis factor-alpha: involvement of muscle myofilaments. Am J Respir Crit Care Med 2002;166(4):479484 .

9. Alamdari N, Toraldo G, Aversa Z, Smith I, Castillero E, Renaud G, et al. Loss of muscle strength during sepsis is in part regulated by glucocorticoids and is associated with reduced muscle fiber stiffness. Am J Physiol Regul Integr Comp Physiol 2012;303(10):R1090-1099.

10. American Thoracic Society; European Respiratory Society. ATS/ ERS statement on respiratory muscle testing. Am J Respir Crit Care Med 2002;166(4):518-624.

11. Heinzmann-Filho JP, Marostica PJ, Donadio MV. Ventilatory muscle strength in cystic fibrosis patients: a literature review. Monaldi Arch Chest Dis 2012;77(3-4):134-138.

12. Dunnink MA, Doeleman WR, Trappenburg JC, de Vries WR. Respiratory muscle strength in stable adolescent and adult patients with cystic fibrosis. J Cyst Fibros 2009;8(1):31-36.

13. Dassios T, Katelari A, Doudounakis S, Mantagos S, Dimitriou G. Respiratory muscle function in patients with cystic fibrosis. Pediatr Pulmonol 2013;48(9):865-873.

14. Hahn A, Ankermann T, Claass A, Mann M, Lindemann H, Neubauer BA. Non-invasive tension time index in relation to severity of disease in children with cystic fibrosis. Pediatr Pulmonol 2008;43(10): 973-981.

15. Hayot M, Guillaumont S, Ramonatxo M, Voisin M, Prefaut C. Determinants of the tension-time index of inspiratory muscles in children with cystic fibrosis. Pediatr Pulmonol 1997;23(5):336-343.

16. VanDevanter DR, O'Riordan MA, Blumer JL, Konstan MW. Assessing time to pulmonary function benefit following antibiotic treatment of acute cystic fibrosis exacerbations. Respir Res 2010;11:137. DOI: $10.1186 / 1465-9921-137$

17. Black LF, Hyatt RE. Maximal respiratory pressures: normal values and relationship to age and sex. Am Rev Respir Dis 1969;99(5):696702 .

18. Wilson SH, Cooke NT, Edwards RH, Spiro SG. Predicted normal values for maximal respiratory pressures in Caucasian adults and children. Thorax 1984;39(7):535-538.

19. Ramonatxo M, Boulard P, Prefaut C. Validation of a noninvasive tension-time index of inspiratory muscles. J Appl Physiol 1995; 78(2):646-653.

20. Gaultier C. Tension-time index of inspiratory muscles in children. Pediatr Pulmonol 1997;23(5):327-329.

21. Wang X, Dockery DW, Wypij D, Fay ME, Ferris BG Jr. Pulmonary function between 6 and 18 years of age. Pediatr Pulmonol 1993; 15(2):75-88

22. Quanjer PH, Tammeling GJ, Cotes JE, Pedersen OF, Peslin R, Yernault JC. Lung volumes and forced ventilatory flows. Report Working Party Standardization of Lung Function Tests, European Community for Steel and Coal. Official Statement of the European Respiratory Society. Eur Respir J Suppl 1993;(16):5-40.
23. Stallings VA, Stark LJ, Robinson KA, Feranchak AP, Quinton H. Evidence-based practice recommendations for nutrition-related management of children and adults with cystic fibrosis and pancreatic insufficiency: results of a systematic review. J Am Diet Assoc 2008; 108(5):832-839.

24. Ramsey BW, Farrell PM, Pencharz P. Nutritional assessment and management in cystic fibrosis: a consensus report. The Consensus Committee. Am J Clin Nutr 1992;55(1):108-116.

25. Frisancho AR. New norms of upper limb fat and muscle areas for assessment of nutritional status. Am J Clin Nutr 1981;34(11):25402545.

26. Pressler T, Bohmova C, Conway S, Dumcius S, Hjelte L, Hoiby N, et al. Chronic Pseudomonas aeruginosa infection definition: EuroCare CF Working Group report. J Cyst Fibros 10 Suppl 2:S75-78, 2011.

27. Govan JR, Deretic V. Microbial pathogenesis in cystic fibrosis: mucoid Pseudomonas aeruginosa and Burkholderia cepacia. Microbiol Rev 1996;60(3):539-574.

28. Divangahi M, Matecki S, Dudley RW, Tuck SA, Bao W, Radzioch D, et al. Preferential diaphragmatic weakness during sustained Pseudomonas aeruginosa lung infection. Am J Respir Crit Care Med 2004;169(6):679-686.

29. Skeletal muscle dysfunction in chronic obstructive pulmonary disease. A statement of the American Thoracic Society and European Respiratory Society. Am J Respir Crit Care Med 1999;159(4 Pt 2):S1-S40.

30. Norman D, Elborn JS, Cordon SM, Rayner RJ, Wiseman MS, Hiller EJ, et al. Plasma tumour necrosis factor alpha in cystic fibrosis. Thorax 1991;46(2):91-95.

31. Elborn JS, Cordon SM, Western PJ, Macdonald IA, Shale DJ. Tumour necrosis factor-alpha, resting energy expenditure and cachexia in cystic fibrosis. Clin Sci (Lond) 1993;85(5):563-568.

32. Fujimura N, Sumita S, Aimono M, Masuda Y, Shichinohe Y, Narimatsu E, et al. Effect of free radical scavengers on diaphragmatic contractility in septic peritonitis. Am J Respir Crit Care Med 2000; 162(6):2159-2165.

33. Poponick JM, Jacobs I, Supinski G, DiMarco AF. Effect of upper respiratory tract infection in patients with neuromuscular disease. Am J Respir Crit Care Med 1997;156(2 Pt 1):659-664.

34. Supinski GS, Callahan LA. Double-stranded RNA-dependent protein kinase activation modulates endotoxin-induced diaphragm weakness. J Appl Physiol 2011;110(1):199-205.

35. Mier A, Redington A, Brophy C, Hodson M, Green M. Respiratory muscle function in cystic fibrosis. Thorax 1990;45(10):750-752.

36. Elliott MW, Mulvey DA, Green M, Moxham J. An evaluation of P0.1 measured in mouth and oesophagus, during carbon dioxide rebreathing in COPD. Eur Respir J 1993;6(7):1055-1059.

37. Fauroux B, Aubertin G, Cohen E, Clement A, Lofaso F. Sniff nasal inspiratory pressure in children with muscular, chest wall or lung disease. Eur Respir J 2009;33(1):113-117.

38. Dufresne V, Knoop C, Van Muylem A, Malfroot A, Lamotte M, Opdekamp C, et al. Effect of systemic inflammation on inspiratory and limb muscle strength and bulk in cystic fibrosis. Am J Respir Crit Care Med 2009;180(2):153-158.

39. Barry PJ, Waterhouse DF, Reilly CM, McKenna TJ, McKone EF, Gallagher CG. Androgens, exercise capacity, and muscle function in cystic fibrosis. Chest 2008;134(6):1258-1264.

40. Pritt B, O'Brien L, Winn W. Mucoid Pseudomonas in cystic fibrosis. Am J Clin Pathol 2007;128(1):32-34.

41. Fauroux B. Why, when and how to propose noninvasive ventilation in cystic fibrosis? Minerva Anestesiol 2011;77(11):1108-1114. 